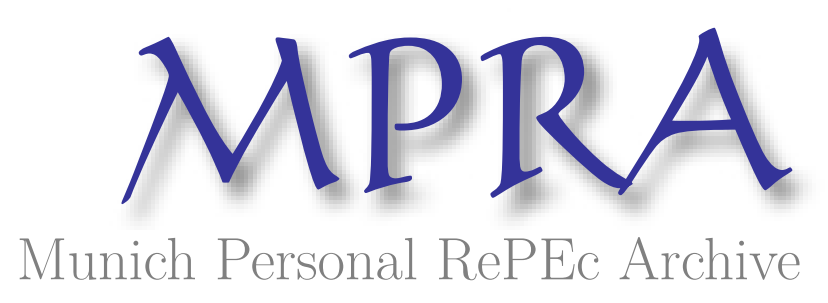

\title{
Impact of Vertical Integration
}

H. Luke, Erin

The University of Wisconsin-Whitewater

7 March 2021

Online at https://mpra.ub.uni-muenchen.de/106490/

MPRA Paper No. 106490, posted 08 Mar 2021 07:37 UTC 


\section{Impact of Vertical Integration}

\section{Erin H. Luke}

The University of Wisconsin-Whitewater

2021

\section{Abstract}

Vertical integration is a powerful, and complex business strategy that when used under the right conditions can positively impact an organization. A company's strategists need to understand what dimensions of integration to use, and the best time to use it. De Beers is a company with a controversial history of being an anti-competitive monopoly. By strategizing into a vertical integrated company De beers has added value to its company by not only targeting the retail, and industrial market, but also the I.T. industry. Forward and backward integration has helped organizations like De Beers maintain control over its inputs and outputs. Rather than just buying all diamond mines, and stock piling the material in order to control the prices, De Beers has embraced change by focusing on new emerging industries. Through vertical strategy and new ownership De Beers is turning its company around in a very competitive luxury industry. Organizations should be aware of the costs of vertical integration when exploring its potential. Bureaucratic costs, and companies becoming too large and inflexible under certain environments can become a problem. Vertical integration is a powerful strategy, but it must always be under scrutiny, and redesigned when the external and internal environment deems change necessary. 


\section{Table of Contents}

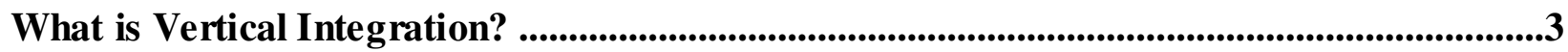

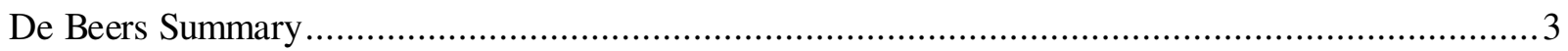

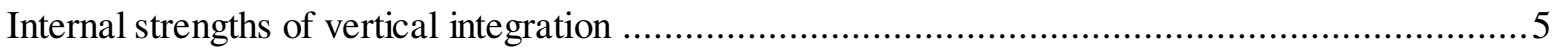

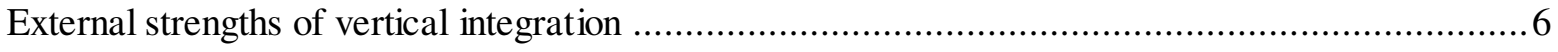

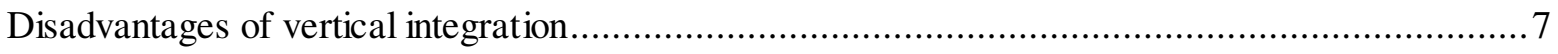

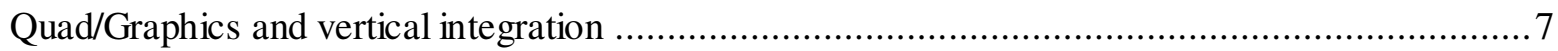

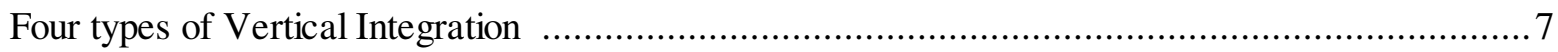

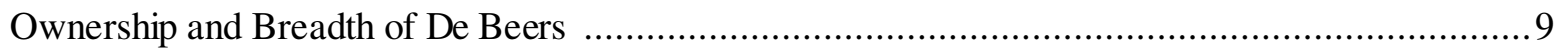

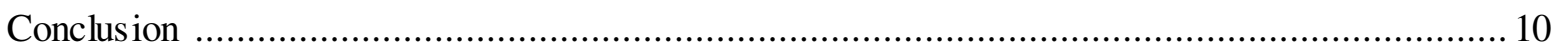

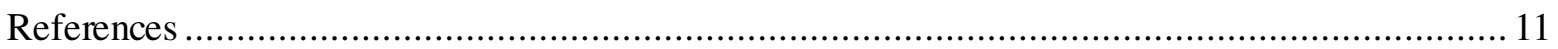




\section{What is Vertical Integration?}

Vertical integration is a powerful corporate strategy that when implemented under the right circumstances can work towards the organizations advantage. Vertical integration describes a firm's control over several or all of the production and or distribution steps involved in the creation of its product or service. This integration takes the assets that was owned by two organizations and combines it into a single business; this creates either a joint ownership, or the sale of one firm's assets to another business. This strategy is more advantageous then contracting with an outside company since usually it creates lower operating costs and more control over quality of its products or services. Forward and backward integration in an organizations' value chain is an attempt to strengthen a company's business model. Although there are different forms of vertical integration, its main approach is either to expand operations backward into an industry that produces inputs for the company, or forward into an industry that distributes the company's products. According to Harrigan (1983/2003), "Vertical integration can vary in breadth, stages, degree, and form" (p. 2). Different vertical integration strategies work well under different conditions, and different contingencies should be considered before deploying a vertical integration strategy. In this paper, I will explore the potential advantages and disadvantages of vertical integration, the different dimensions of vertical integration that was researched by Harrigan, and finally, I will go more in depth on how the form of ownership and stages has an impact when companies like De Beers reorganizes its company.

\section{The Diamond Industry}

The diamond giant De Beers may have the longest history of any international cartel. De Beers that began as a company in 1888 has a lengthy record of unscrupulous organizational ethics and social responsibility. In recent years, the global environment has become too volatile 
for De Beers to continue on its monopolistic path. De Beers has redesigned its business strategy for the $21^{\text {st }}$ century, which has drastically improved its organizations competitive advantage. This new restructuring of De Beers now fosters innovation of its products and services now more than ever before. Although De Beers has recently redesigned its diamond mining conglomerate so it no longer runs as a monopoly, its forward-thinking innovations could keep De Beers ahead of its competitors for many years to come. The development of a new corporate-level strategy at De Beers has potential benefits since it is helping the company be more responsive to changes in the market. De Beers was forced to make changes to its company's structure and strategy. From the time when the synthetic diamond was invented and brought onto the market the company has been losing money. In reaction to the synthetic diamonds De Beers added a technology research division called Element Six to its conglomerate. Ideally, Element Six will develop new innovations that will reinvent De Beers from its past as a horizontal monopoly into a technological leader. According to Mims (2011) perceptions on De Beers new strategy:

And so De Beers appears to have finally accepted that some day soon, the world will be flooded with more synthetic diamonds than "real" ones, by many orders of magnitude. (The two are chemically indistinguishable.) De Beers, ever enterprising, aims not merely to dominate the market for synthetic diamond, but to create it. To do that, it needs IT innovators to start thinking about what they would do if they had unlimited quantities of diamond at their disposal. To that end, De Beers recently opened a Silicon Valley VC shop that has already dropped "tens of millions" of dollars on a portfolio of seven companies. Where's all this going? Diamond microchips. Diamond is the best thermal conductor on the planet, which means diamond microchips could run ultra-hot without requiring a conventional cooling system. This would lead to considerable energy savings. 
It would also mean chips running at $81 \mathrm{GHz}$. (How the World's Oldest Diamond

Monopoly is Trying to Become an IT Juggernaut)

\section{Potential Internal Strengths of Vertical Integration}

Operating costs are ideally lowered when strategizing a vertical integration since there is more internal coordination within the organization. There is an improved efficiency throughout the production of the product or service since there is a tighter control over more steps in the supply chain. Transaction costs are usually reduced in vertical integration since some steps in the production or distribution of the firms' value creation are eliminated. The Diamond company saves time and money today by selling its own jewelry in De Beers branded stores, rather than just relying on the whole sale of diamonds to bring value to the company.

The quality of products and services are better in vertical integration since the organization now has control over all steps of the process, rather than relying on a contracted firm. For example, De beers has control over the value chain from the ownership of the mines in Africa to the retail and branding of the final product placed in front of the customer. This is beneficial to De Beers since they control the quality and variety of diamonds they will place into the market, and how their company will have product differentiation.

This also creates better security for a company with confidential technology, or valuable supplies. In the output domains security is under tight control and the organization can be insulated from market disruptions. De beers uses this strategy to their advantage by creating technology to mine diamonds where other companies would normally find impossible. De Beers develops machines to mine in water and caves and other out of reach areas. This proprietary information is secure since it stays within the organization. According to Jones's (2013) insights on the benefits of vertical integration: 
An organization that supplies its own inputs and/or disposes of its own outputs may be able to keep for itself the profits previously earned by its independent suppliers and distributors. Moreover, production cost savings often arise when an organization owns its suppliers because, for example, inputs can now be designed so they can be assembled at a lower cost. Also, because it now controls the reliability and quality of inputs, this can save an organization a great deal of money if products eventually have to be repaired under guarantee. (pp.225-226)

\section{Competitive (external) Advantage}

Having more control over the environment is a big factor for organizations to develop a vertical strategy. Having certainty of supplies of materials and services, and better control over the distribution is a great advantage.

According to Blois (1972), "The importance and validity of such advantages will depend upon the specific situation considered, but in each case the benefits must be weighed against disadvantages which are bound to arise and typically will include some of the following:

1. Disparities between productive capacities at various stages of production

2. Public opinion and governmental pressure

3. Lack of specialization

4. Inflexibility of operations

5. Extension of the management team

6. Lack of direct competitive pressures on the costs of intermediate products" (p. 254).

Being more responsive to the changes in market needs and trends is a strong advantage of vertical integration. De Beers used this strategy recently by improving their marketing and technology model. In the past, De Beers focused mainly on the mining and whole sale of 
diamonds. Today De Beers focuses on a balanced vertical integration where there is modernization of marketing to the customer in retail stores and innovative technology developing new computer chips based off of diamonds being a good thermal conductor.

\section{Potential Disadvantages of Vertical Integration}

Although there are many advantages to vertical integration, companies should be aware of bureaucratic costs when the organization owns all firms in its strategy. Fully vertical integrated companies are at greatest risk of raising their bureaucratic costs. Although there is more quality in the products developed in a vertical integration, in large companies there could be a lack of incentive for suppliers to watch cost. When the organization becomes larger, communication between divisions becomes increasingly difficult. Managers negotiating and monitoring activity within departments can become expensive and slow down action that creates value for a company.

\section{Quad/Graphics and vertical integration}

Quad/Graphics is a global commercial printer that is based in Sussex, WI. Quad/Graphics was incorporated in 1971, and provides services related to printing and media development. Although the print industry has been challenged since the digital age where most people prefer to get their media from online source, Quad/Graphics has survived with revenue of $\$ 3.4$ billion in 2010. As Quad/Graphics perfects and develops its vertical integration, much of its strategy can be seen in Harrigan's description of the vertical integration dimensions.

\section{The Four types of Vertical Integration}

When an organization decides to develop a strategy for a vertically integrated company there are a variety of forms to consider. The vertical integration of the companies does not necessarily need to be $100 \%$ owned by the main organization for it to be an efficient business 
model. According to Harrigan there are four different ways vertical integration can vary including breadth, stages, degree, and form.

Breadth: The breadth of vertical integration refers to how much, or which activities a firm is doing in-house. An example of breadth would be how Quad/Graphics a large commercial printer in Wisconsin not only creates its own ink, but also has a subsidiary department to design and produce collateral.

Stages: In Stages of vertical Integration are the numbers of steps an organization may or may not undertake. For instance, if Quad/Graphics owns technology that gives them a competitive edge it may add more stages to their process. Digital printing is developing into big business for printers. One of the factors that make this so popular is that each print job is customizable. The ability to customize each print comes from computer software that Quad/Graphics makes and maintains itself. The software development, and maintenance would be another stage in Quad/Graphics integration.

Degree: The degree of integration refers to what degree an organization preforms actives inhouse. For example, Quad/Graphics may create its own ink in its owned laboratory's, but it buys its paper from outside sellers.

Form: Is the form of ownership the vertical relationship takes. Form refers to how much a firm owns another business. A business could be fully integrated (not relying on outside suppliers) or have taper vertical integration where a company may use outside suppliers or independent distributors to get their product or service onto the market. For example, the relationship could be $100 \%$ ownership, or a joint venture. There could also be no ownership, creating a kind of Quasi-Vertically integrated company. 


\section{Ownership and Breadth in De Beers Strategy}

In recent years the international diamond mining company has gone under extreme reorganization. Since the early 1900's the Oppenheimer family controlled the De Beers organization and dominated the industry with a horizontal monopoly. In 2000 De Beers lost its monopoly when mines where found and diamonds were sold outside the De Beers cartel. Since De beers lost control over important mines, and synthetic diamonds were becoming popular, it became obvious that De beers had to change its business model. According to Wachman (2011), "Mining giant Anglo American has swooped for a controlling stake in De Beers, the biggest diamond distributor in the world, spending $£ 3.2$ bn on the $40 \%$ holding owned by South Africa's Oppenheimer family. Anglo, which already speaks for $45 \%$ of De Beers, will emerge with $85 \%$ once the deal is completed in a move that will give it a leading role in the global diamond market".

The breadth in the De Beers corporations is very broad today. De beers owns their mines across the world, controls who the diamonds are sold to, Controls the branding and retail image of the jewelry developed by the company. De beers is a very broadly integrated company, where many of its activities, such as inputs, services are under De Beers control. This is to De Beers benefit since it will ultimately help De beers with product differentiability.

The broadly integrated company of De Beers is also advantageous since it helps maintain product quality and design secrecy. De Beers can guaranty that the diamonds sold in its stores are up to par with its competitors. Quality is very important in the diamond industry. De Beers created the "Best Practices Principles", and uses these as guidelines when doing business and selecting their "suppliers of Choice". Secrecy can be important to a company like De Beers when developing new technology directly to the diamonds, or developing new services such as uses 
diamonds in the I.T. field for computer chips. This broad integration into the I.T. field is a great move for De Beers since during an economic recession sales of luxury goods goes down drastically.

In conclusion, vertical integration is a powerful, and complex business strategy that when used under the right conditions can positively impact an organization. A company's strategists need to understand what dimensions of integration to use, and the best time to use it. De Beers is a company with a controversial history of being an anti-competitive monopoly. By strategizing into a vertical integrated company De beers has added value to its company by not only targeting the retail, and industrial market, but also the I.T. industry. Forward and backward integration has helped organizations like De Beers maintain control over its inputs and outputs. Rather than just buying all diamond mines, and stock piling the material in order to control the prices, De Beers has embraced change by focusing on new emerging industries. Through vertical strategy and new ownership De Beers is turning its company around in a very competitive luxury industry. Organizations should be aware of the costs of vertical integration when exploring its potential. Bureaucratic costs, and companies becoming too large and inflexible under certain environments can become a problem. Vertical integration is a powerful strategy, but it must always be under scrutiny, and redesigned when the external and internal environment deems change necessary. 


\section{References}

Blois, K. J. (1972, July). Vertical Quasi-Integration. 20 . Blackwell Publishing. Cadieux, D. (2005). De Beers and the global diamond industry. Canada.

Harrigan, K. R. (2003). Vertical Integration, Outsourcing and Corporate Strategy. Beard Books. Jones, G. R. (2013). Organizational Theory, Design, and Change (Seventh ed.). USA: Pearson. Mims, C. (2011, October 25). How the World's Oldest Diamond Monopoly is Trying to Become an IT Juggernaut. Retrieved from MIT Technology Review:

http://www.technologyreview.com/view/425921/how-the-worlds-oldest-diamond- monopoly-istrying-to-become-an-it-juggernaut/

Wachman, R. (2011, November 4). Anglo American Gains Controlling Stake in De Beers.

Retrieved from The Guardian: http://www.guardian.co.uk/business/2011/nov/04/anglo-americandebeers-diamonds 